\title{
Analyses of Carbon and Activated Carbon Nanofiber Web
}

\author{
Pelin ALTAY, Zeynep Burcu CAVDAR, Nuray UCAR, Nilgun KARATEPE YAVUZ
}

\begin{abstract}
This paper focuses on the morphological, thermal and structural properties of the activated carbon fibers (ACFs) after carbonization and activation and also stabilization process. PAN based carbon nanofibers were produced by electrospinning process followed by heat-treatments (stabilization, carbonization and activation process). Scanning electron microscopy (SEM), Thermogravimetric Analysis (TGA) and Fourier Infrared Spectroscopy (FT-IR) were used for characterization of electrospun ACFs and loss weight was also calculated. The results show that the structure of ACFs becomes more stable after carbonization and also activation+carbonization process by increasing the yield of carbon atoms, as compared with untreated and stabilized PAN nanofiber. The diameter of fiber decreases after carbonization and activation process.
\end{abstract}

Keywords - carbon fiber, activated carbon web, electrospinning

\section{Introduction}

Activated carbon fibers (ACFs) have received increasing attention in recent years as an adsorbent based on their microporous structure, high pore size distribution, large surface area, adsorption capacity, fast adsorption/desorption rates, the ability of adsorption at very low concentrations of adsorbates and great flexibility. This activated carbon is prepared from natural or synthetic precursors. Several organic sources can be useful as precursor for the production of ACFs such as polyvinyl alcohol, phenolic resins, polyimides, polyacrylamides, pitch, cellulose, and polyacrylonitrile (PAN), poly(vinylidene fluoride) by applying physical and chemical methods of treatment [1-7].

Pelin Altay, Nuray Ucar

Textile Engineering Department, Istanbul Technical University Turkey

Zeynep Burcu Cavdar

Nano Science and Nano Engineering Department, Istanbul Technical University,

Nilgun Karatepe Yavuz

Energy Institute, Istanbul Technical University
The main objective of this paper is to investigate the morphological, thermal and structural properties of the ACFs after carbonization and activation and also stabilization process. In this study, PAN based carbon nanofibers were produced by electrospinning process followed by heattreatments (stabilization, carbonization and activation process). Electrospun ACFs were characterized by Scanning electron microscopy (SEM), Thermogravimetric Analysis (TGA) and Fourier Infrared Spectroscopy (FT-IR) and loss weight was also measured.

\section{Materials and Methods}

Polyacrylonitrile was obtained from Sigma Aldrich to use as precursor of carbon nanofiber webs. N,N-dimethylformamide (DMF) was purchased from Merck Company. Nitrogen was used as inert gas during the carbonization and carbon dioxide gas was used during activation.

\section{Production of PAN based nanofiber webs via electrospinning}

Dry spun poliakrilonitril (PAN) fiber was used as a raw material to produce PAN based carbon nanofiber. PAN precursor was dissolved in $\mathrm{N}, \mathrm{N}$-dimethylformamide in a weight ratio of $15 \mathrm{wt} . \%$ by stirring for $5 \mathrm{~h}$ at $65{ }^{\circ} \mathrm{C}$, then PAN solution was transferred into a $10 \mathrm{~mL}$ syringe. The electrospinning was conducted using flow rate of $1.0 \mathrm{~mL} / \mathrm{hr}$, with an applied voltage of $15 \mathrm{kV}$ and $10 \mathrm{~cm}$ spinning distance. Electrospun samples were subjected to stabilization, carbonization and activation process.

A schematic diagram of electrospinning process is given in Fig. 1. Electrospinning is a method based on the use of electrostatic forces on free charges on the surface or inside a polymeric liquid for producing continuous nanofibres. 
Proc. of The Third Intl. Conf. On Advances in Applied Science and Environmental Technology - ASET 2015 Copyright (C) Institute of Research Engineers and Doctors, USA .All rights reserved.

ISBN: 978-1-63248-084-2 doi: 10.15224/ 978-1-63248-084-2-92
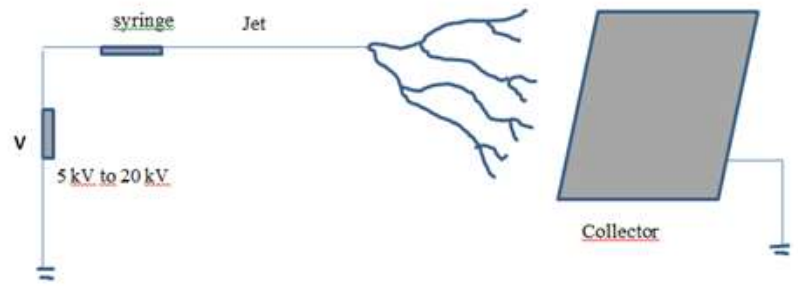

Figure 1. Diyagram of electropsinning setup

\section{Stabilization, carbonization and $\mathrm{CO2}$ activation}

PROTHERM PLF series chamber furnace was used for stabilization. Activation and carbonization processes were performed by using PROTHERM PTF series tube furnace.

\section{Characterization of PAN based carbon nanofiber webs}

The electrospun ACF webs were examined using Fourier Infrared Spectroscopy (FT-IR), Thermogravimetric Analysis (TGA), Scanning Electron Microscopy (SEM and EDX). Losses in weight during the production were also measured.

\section{Fourier Infrared Spectroscopy (FT-IR)}

FT-IR analysis was performed using Perkin Elmer with UATR Accessory in the range between $400 \mathrm{~cm}-1$ and $4000 \mathrm{~cm}-1$ and the structural changes of material were evaluated according to the results.

\section{Thermogravimetric Analysis (TGA)}

Perkin ElmerTA Q50 thermal gravimetric analyser was used for thermal analysis. After keeping the samples at $500 \mathrm{C}$ for one minute, they were heated to $850^{\circ} \mathrm{C}$ with $20^{\circ} \mathrm{C} / \mathrm{min}$ by thermal gravimetric analyser.

\section{Scanning Electron Microscopy (SEM and EDX)}

PAN precursor webs, stabilized webs, carbonized webs and activated webs were observed by using scanning electronic microscopy (SEM). The magnification of the microscopy was fixed to $10000 x$ to compare all samples.

\section{Experimental}

\section{A. Stabilization of PAN based carbon nanofiber webs}

The PAN based nanofiber webs were placed into the furnace (PROTHERM PLF) with tension in pressured air atmosphere. The temperature of the furnace was set on $265^{\circ} \mathrm{C}$ at a heating rate of $10 \mathrm{C} / \mathrm{min}$. At this temperature, samples were stabilized for 24 hours.

\section{B. Carbonization}

The stabilized PAN nanofiber was placed in tube furnace and carbonized at $8000 \mathrm{C}$ for 45 minutes in nitrogen gas with a heating rate of $5^{\circ} \mathrm{C} / \mathrm{min}$.

\section{Carbonization and activation of PAN based carbon nanofiber webs}

PAN based carbon nanofiber webs which were stabilized for 24 hours were placed in tube furnace under nitrogen atmosphere and the temperature of the furnace was increased from room temperature to $800^{\circ} \mathrm{C}$ with $5^{\circ} \mathrm{C} / \mathrm{min}$ for 15 minute. Then the samples were kept in a $\mathrm{CO} 2$ atmosphere for 30 minutes and activation process was completed. The furnace was cooled to room temperature, cutting $\mathrm{CO} 2$ and feeding nitrogen gas continuously into the furnace.

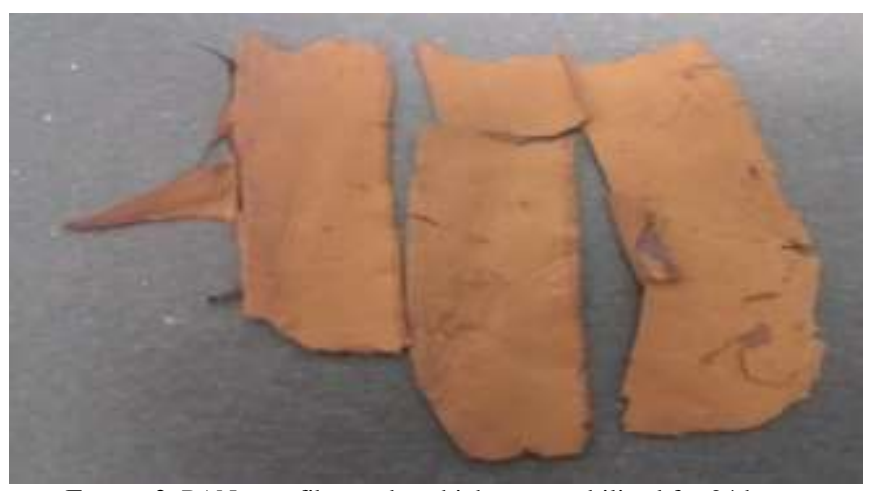

Figure-2. PAN nanofiber webs which were stabilized for 24 hours 
Proc. of The Third Intl. Conf. On Advances in Applied Science and Environmental Technology - ASET 2015 Copyright (C) Institute of Research Engineers and Doctors, USA .All rights reserved. ISBN: 978-1-63248-084-2 doi: 10.15224/ 978-1-63248-084-2-92

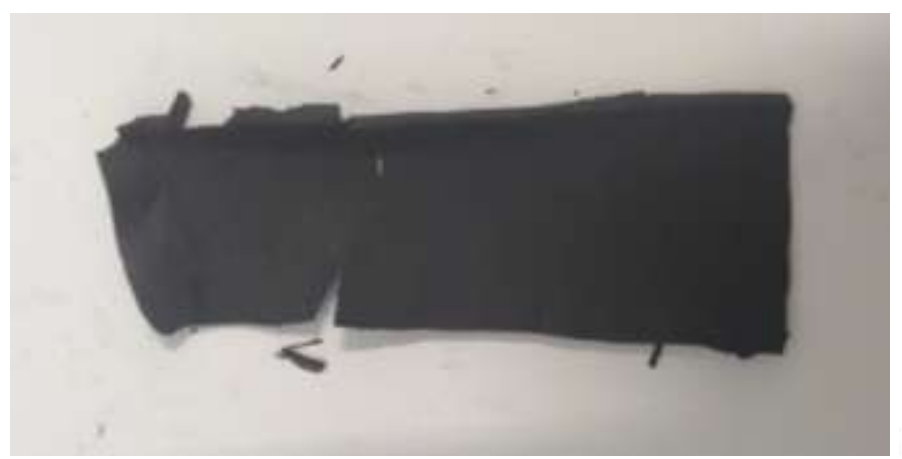

Figure-3.Stabilized PAN based carbon nanofiber which was carbonized in nitrogen gas for $45 \mathrm{~min}$.

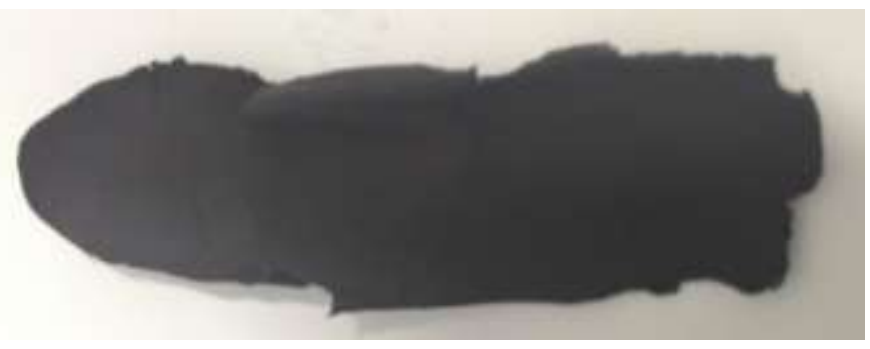

Figure-4.Stabilized PAN nanofiber webs which were subjected to carbonization and activation

\section{Iv. Results and Discussion}

\section{Characterization of PAN based carbon nanofiber webs}

Table-1.Sample names based on the conditions and steps of the processes for the production of activated PAN based carbon nanofiber

\begin{tabular}{|c|c|c|}
\hline $\begin{array}{c}\text { Sample } \\
\text { code }\end{array}$ & Sample name & Description of process \\
\hline PAN1 & Reference 1 & ------ \\
\hline PAN2 & Reference 2 & 24h stabilized \\
\hline $\begin{array}{l}\text { PAN- } \\
\text { AC }\end{array}$ & $\begin{array}{c}\text { Carbonization + } \\
\text { Activation }\end{array}$ & $\begin{array}{c}5^{\circ} \mathrm{C} / \mathrm{min}, 800^{\circ} \mathrm{C}, 15 \\
\min 514 \mathrm{ml} / \min \mathrm{N}_{2}+ \\
30 \min 150 \mathrm{ml} / \min \mathrm{CO}_{2}\end{array}$ \\
\hline PAN-C & Carbonization & $\begin{array}{l}5^{\circ} \mathrm{C} / \min , 800^{\circ} \mathrm{C}, 45 \\
\min 514 \mathrm{ml} / \min \mathrm{N}_{2}\end{array}$ \\
\hline
\end{tabular}

\subsection{Fourier Infrared Spektroskopisi (FT-IR)}

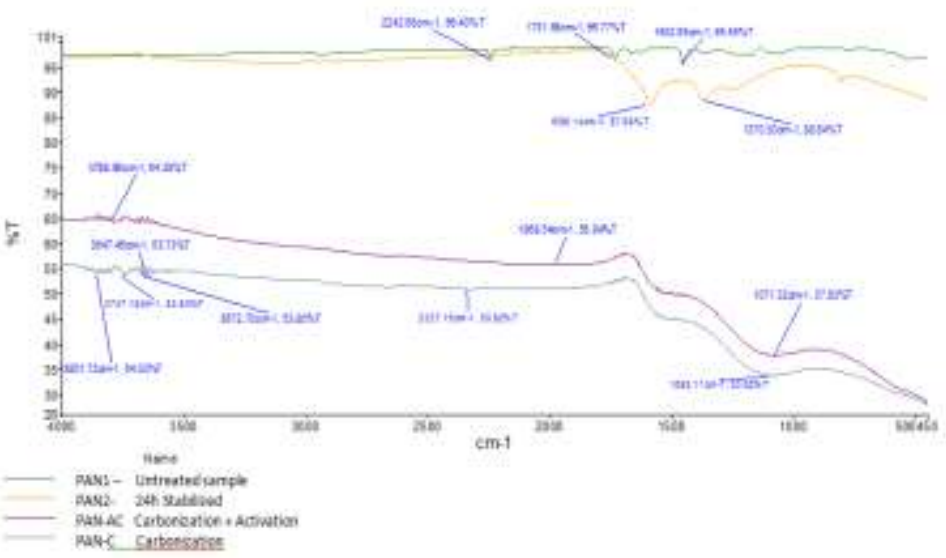

Figure-5. Comparison ofFT-IR results of PAN1, PAN2, PAN-AC and PAN-C

According to figure 5, for the untreated PAN-based nanofibres the spectrum gives a peak at 2900-3000 cm-1 of which represents an uncertain $\mathrm{C}-\mathrm{H}$ bond, a peak at $2242.62 \mathrm{~cm}$ 1representing $\mathrm{C} \equiv \mathrm{N}$ or $\mathrm{C} \equiv \mathrm{C}$ and a peak at $1731.66 \mathrm{~cm}-1$ representing $\mathrm{C}=\mathrm{O}$ bond and another peak at $1452.55 \mathrm{~cm} 1$ representing $\mathrm{C}=\mathrm{C}$ bond. However, for the sample which was subjected to 24 hours of stabilization, these bonds were not seen. For this sample, aromatic carbon atoms give a peak in the range of 1550-1600 cm-1, indicating the beginning of the aromatization reaction. The peak observed at $1370 \mathrm{~cm}-1$ for 24h stabilized sample represents - CH3 bond.

Furthermore, by looking at the graph for PAN1 and PAN2, it was observed that about between ninety and ninety five percentage of the transmitted ray was passed. This arises from the fact that the color of both untreated sample and $24 \mathrm{~h}$ stabilized sample were convenient for passing the light. Samples subjected to carbonization and activation (PAN-AC and PAN-C), the percentage of transmitted light decreased to fifty percent because of the black color of samples. PAN-AC and PAN-C show oscillations below the peak value of 3500 $\mathrm{cm}-1$ that may be caused from the noise. These oscillations may be arised from a sound coming from the device or entrapped air in the structure of material.

For PAN-AC, a peak, representing $\mathrm{C}=\mathrm{C}$ bond, formed in point of $1968.5 \mathrm{~cm}-1$. PAN-C shows a peak, indicating the presence of $\mathrm{CO} 2$, at $2327.15 \mathrm{~cm}-1$

\subsection{Termogravimetrik Analiz (TGA)}

Figure 6 shows the thermal stability of PAN based carbon nanofiber webs by monitoring the weight change that occurs as the specimen was heated. It was seen that ACFs can withstand up to $300{ }^{\circ} \mathrm{C}$. Heating above $300{ }^{\circ} \mathrm{C}$ caused a sharp decrease in total weight of sample. 
Proc. of The Third Intl. Conf. On Advances in Applied Science and Environmental Technology - ASET 2015 Copyright (C) Institute of Research Engineers and Doctors, USA .All rights reserved.

ISBN: 978-1-63248-084-2 doi: 10.15224/ 978-1-63248-084-2-92

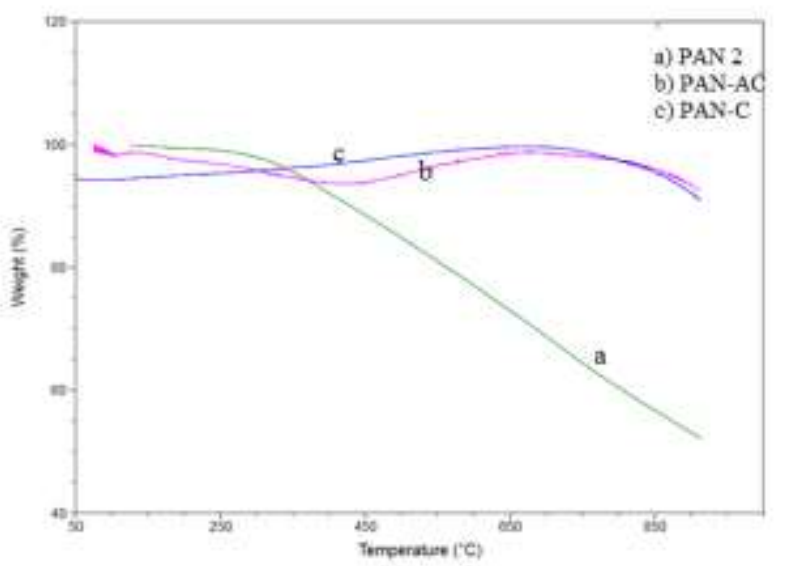

Figure-6. TGA spectrum of PAN2, PAN-AC and PAN-C

\subsection{Scanning Electron Microscopy (SEM)}

The morphology of the product was observed by scanning electron microscopy (SEM) and the SEM images of the ACF webs obtained are shown in Fig. 7. The nanofibers in the ACF webs have a regular and flexuous fibrous morphology, of which the diameter becomes smaller as the carbonization and activation process was applied.
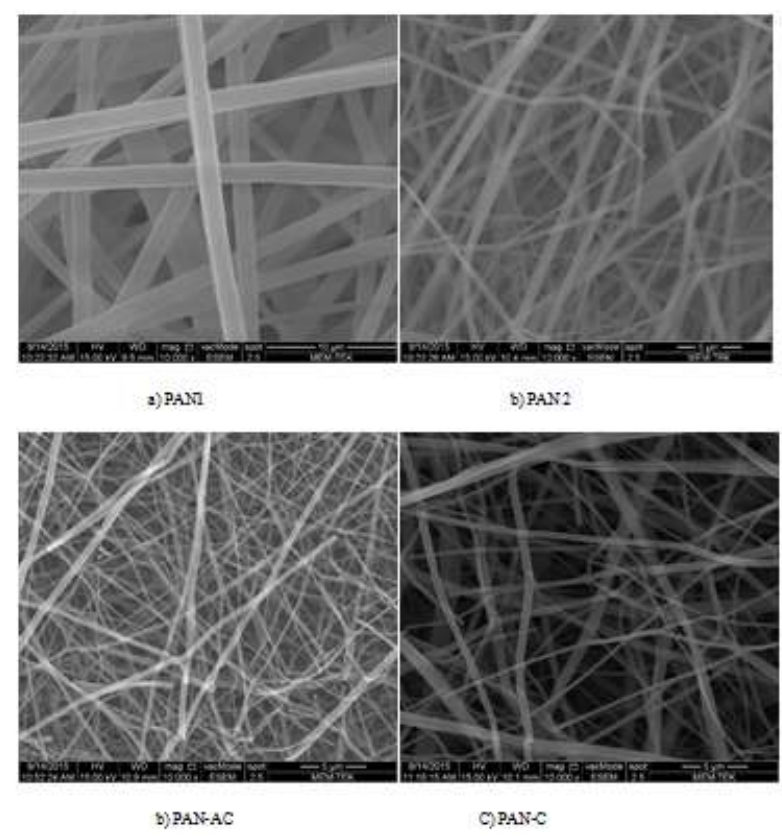

Figure 7: SEM images of PAN1, PAN2, PAN-AC and PAN-C
Table-1. Standard deviation, average nanometer and coefficient of variation $(\mathrm{CV})$ values of the fiber diameters in the SEM images

\begin{tabular}{|c|c|c|c|c|}
\hline $\begin{array}{c}\text { Sample } \\
\text { Name }\end{array}$ & Method & $\begin{array}{c}\text { Standart } \\
\text { deviation }\end{array}$ & $\begin{array}{c}\text { Average } \\
\text { nanometer }\end{array}$ & $\begin{array}{c}\text { Coefficient } \\
\text { of } \\
\text { variation } \\
(\boldsymbol{C V})\end{array}$ \\
\hline PAN1 & Reference 1 & 259,98 & 1447,66 & 17,95 \\
\hline PAN2 & $\begin{array}{c}\text { Reference } 2 \\
\text { (24h } \\
\text { stabilization) }\end{array}$ & 147,97 & 778,83 & 19,00 \\
\hline $\begin{array}{c}\text { PAN- } \\
\text { AC }\end{array}$ & Metod -3 & 101,66 & 394,166 & 25,79 \\
\hline PAN-C & Metod -4 & 94,30 & 336,83 & 27,99 \\
\hline
\end{tabular}

In Figure 7 and Table 1, it was shown that carbonization and activation processes cause decrease in fiber diameter. This results from the aromatization during the stabilization and increases in bonding forces of the fibers because of the dehydrogenation reactions. With dehydrogenation reactions, certain atoms in the fiber structure separate from the fiber by reacting with free oxygen in the medium.

It was shown that carbonization process has a positive effect on distribution of the fiber diameter and fiber structure. It was clearly observed that carbonization causes decrease in fiber diameter and provides uniform fiber distribution.

\subsection{Measurement of weight losses}

Weights of PAN based carbon nanofiber in each process step were measured and weight losses were calculated before and after treatment. 55-65\% of total weight losses were obtained after the carbonization and activation processes. These results are consistent with the literature. It is clearly seen that when the activation process was performed, weight loss was slightly increased.

Tablo-2.Weights, weight losses and percentage of weight losses of PAN based carbon nanofiber before and after treatment

\begin{tabular}{|c|c|c|c|c|}
\hline & $\begin{array}{c}\text { PAN } \\
(\% 15) \\
\text { before } \\
\text { treatment } \\
(\mathbf{g})\end{array}$ & $\begin{array}{c}\text { PAN(\% 15) } \\
\text { after } \\
\text { treatment } \\
(\mathbf{g})\end{array}$ & $\begin{array}{c}\text { Weight } \\
\text { losses (g) }\end{array}$ & $\begin{array}{c}\text { Percentage } \\
\text { of weight } \\
\text { losses (\%) }\end{array}$ \\
\hline $\begin{array}{c}\mathbf{2 4} \text { h } \\
\text { stabilization }\end{array}$ & 0,1224 & 0,1039 & 0,0185 & 15,1144 \\
\hline PAN-AC & 0,0685 & 0,0083 & 0,0602 & 87,88 \\
\hline PAN-C & 0,1375 & 0,0659 & 0,0716 & 52,1 \\
\hline
\end{tabular}

\section{Conclusion}

The aim of the present investigation was to characterize the structure of PAN-based CNFs using Fourier Infrared Spektroskopisi (FT-IR), Termogravimetrik Analiz (TGA) and Scanning electron microscopy (SEM). The results show that 
each step of stabilization, carbonization and activation result to decrease of weight of PAN nanofiber and decrease of fiber diameter. After carbonization and also activation+carbonization process, structure becomes more stable compared to untreated and stabilized PAN nanofiber, due to carbon based structure according to TGA and FTIR result. PAN-based CNFs are promising a new class of materials used in a wide range of applications such as volatile organic compounds (VOCs) adsorption, material reinforcements, garments, insulators, medical and energy storage devices, and etc.

\section{Acknowledgment}

This work was supported by the ITU Scientific Research Project of Turkey (BAP) under the Project no 38332. The authors would like to thank ITU BAP for financial support.

\section{References}

[1] Rahaman M.S.A., Ismail A.F., Mustafa A. (2007). A review of heat treatment on polyacrylonitrile fiber, Polymer Degradation and Stability, 92, 1421-1432.

[2] Wiles KB. Determination of reactivity ratios for acrylonitrile/methyl acrylate radical copolymerization via nonlinear methodologies using real time FTIR. MSc thesis, Faculty of the Virginia Polytechnic Institute and State University: Blacksburg, Virginia; 2002.

[3] Pamula E, Rouxhet GP. Bulk and surface chemical functionalities of type III PAN-based carbon fibers. Carbon 2003; 41(10):1905-15.

[4] Yun J., Kim B., Yang K. S., Bang Y. H., Kim S. R., and Woo H. (2009). Process Optimization for Preparing High Performance PAN-based Carbon Fibers, Bull. Korean Chem. Soc. 2009, Vol. 30, No. 10.

[5] Schwartz M. Encyclopedia of materials, parts, and finishes. 2nd ed. Boca Raton, Florida: CRC Press; 2002.

[6] Nataraj S.K., Yang K.S., Aminabhavi T.M. (2012), Polyacrylonitrile-based nanofibers-A state-of-theart review, Progress in Polymer Science 37 , 487-513.

[7] Karacan I.and Erdogan G. (2012). The Influence of Thermal Stabilization Stage on theMolecular Structure of Polyacrylonitrile Fibers Prior to the Carbonization Stage, Fibers and Polymers, Vol.13, No.3, 295-302. 